\title{
Unravelling the relationship between a firm's big data analytics capability and the realization of a competitive advantage: an IT business value approach
}

\author{
Pieter De Rijck \\ University of Antwerp, Belgium \\ pieter.derijck@uantwerpen.be
}

\begin{abstract}
Big Data Analytics (BDA) has the potential to transform business models, firms and the competitive landscape. Though, creating value from BDA investments seems challenging as many technical and managerial challenges are involved. Due to its complexity, the value generated from big data depends on how well a firm's Big Data Analytics Capability $(B D A C)$ is developed. Drawing on the Resource Based View $(R B V)$, the IT business value approach and the $B D A C$ literature, we study the relationship between a firm's $B D A C$ and the realization of a competitive advantage. We used survey data from multiple respondents per firm (i.e. IT managers and Business managers) in 112 Belgian and Dutch firms. Using PLS-SEM, we found a direct relationship between a firm's BDAC and the perceived realization of a competitive advantage. We also found a partial mediation of this relationship via the performance of the firm's operation management process.
\end{abstract}

\section{Introduction}

A study by Accenture shows that no less than $87 \%$ of the companies believe that BDA (big data analytics) will redefine the competitive landscape of their industries at short notice [1]. As a result, the number of firms investing in data analytics to improve their competitive advantage and performance is growing [2]. These firms believe that BDA will generate insights from their datasets which will help them to improve their performance [3]. However - due to technical and managerial challenges - firms have difficulties to successfully deploy their BDA investment [4] or consider BDA as complex and overwhelming [5]. Examples of barriers and challenges are omnipresent [6]: data processing bottlenecks and complexity, legacy IT systems, management of different data formats, lack of data analytics skills among staff and a lack of understanding how BDA can improve business performance, ... Not surprisingly, only $27 \%$ of the companies that invested in data analytics considered their investment to be successful [7].

According to $\mathrm{Hu}$ et al. [8] the value generated from big data depends on how well a firm's big data analytics capability (BDAC) is developed. In recent years there have been a number of studies that have focused on the development of a big data analytics capability measurement instrument $[9,10]$. Côrte-real et al. [11] launched a call for research to understand the path between a firm's BDAC and the realization of a competitive advantage. Responding to this call, we adopt a process-level approach to unravel whether a firm's BDAC is directly associated with a firm's competitive advantage or whether the relationship is mediated by underlying mechanisms which is consistent with the IT business value process perspective which argues that organizational level impact of IT (i.e. the realization of a competitive advantage) is realized through the intermediate process level contribution [12, p. 626]

Hence, using unique survey data collected from multiple respondents per firm, we study the following research questions:

RQ1: Is a more developed BDAC associated with a a stronger competitive advantage?

RQ2: Is the impact of BDAC on a firm's competitive advantage mediated by improved Operations Management Process (OMP) performance, Customer Management Process (CMP) performance and/or Innovation Management Process (IMP) performance?

The remainder of the paper covers following topics. Section 2 provides a short review of the literature on the development of a BDAC and the relationships with firm outcome variables. Section 3 presents the hypothesis development. Section 4 outlines the research methodology and describes the data collection procedure. Section 5 presents the results. Next, results are discussed and concluded in section 6. 
Finally, in section 7 and 8 respectively, we outline implications (for both theory and practice) and limitations.

\section{Literature}

\subsection{Big Data Analytics Capability (BDAC)}

Big Data is defined on the basis of the so-called four V's: volume, velocity, variety and veracity [13]. Big Data thus adds new dimensions to analytics which simultaneously requires adapted human skills and technical resources to its unique characteristics [4]. It is argued that, in order to capitalize the potential role BDA can play in an organization, BDA requires the following elements: a data-driven culture, new technological techniques and human competencies [9]. Thus, a firm's BDAC implies a unique blend of its financial physical, human, and organizational resources to create a capability, which is difficult to match by competitors [10]. Cosic et al. [14, p. 4], defined BDAC as "the ability to utilize resources to perform a business analytics task, based on the interaction between IT assets and other firm resources." As a result, the adoption of BDA comes along with significant challenges from a managerial and cultural point of view [15].

\subsection{The impact of BDAC on the organization}

Our study aims to investigate the relationship between a firm's BDAC and the perceived realization of a competitive advantage and how this relationship is mediated by the performance of three internal business processes: operational, customer and innovation management process performance. We study current research on differences in the BDAC construct definition, the firm level outcome choice (as dependent variable) and how scholars tried to unravel this relationship by means of (a) mediating variable(s).

The first focus of the literature review relates to the way in which BDAC is operationalized. Via the SCOPUS database, we found 50 articles (45 journal articles and 5 conference papers) based on the keywords "Big Data Analytics Capability" and "Big Data Analytics Capabilities". All of them were in the domain "Business, Management and Accounting" and published since 2014. The final selection was limited to 24 articles based on abstract screening. An article was removed from the selection if it did not aim to study the relationship between BDAC and an organizational outcome. 10 out of 24 studies measure BDAC as a first order construct. This means that the authors do not make a distinction between different types of resources (i.e. second and third order constructs) Another 10 out of 24 studies do measure
BDAC as a third order construct which avoids oversimplification of a firm's BDAC. The third-order measurements draw on the IT capability literature conceptualizing a firm's IT capability as a combination of IT infrastructure/tangible resources, human IT resources (both managerial and technical) and intangible IT resources [16].

Of all papers studied, only five scholars have adopted BDAC as a formative third-order construct. This is somewhat surprising when applying the four decision rules (formative vs. reflective) on the BDAC construct $[16,17]$. Most important arguments: the second-order constructs (i.e. tangibles, human and intangible resources) are characteristics (formative) instead of manifestations (reflective) of the BDAC. Second, each of the three second-order constructs capture a distinct facet (formative) of the BDAC and are thus not interchangeable (reflective). Since we want to gain insight into the building blocks of a BDAC, we adopt the formative measurement of Gupta \& George [10]. This measurement is appropriate for our study as they followed the classification of Grant (1991) [19] which allows us to disentangle among differences between tangible, intangible and human resources. Their measurement was empirically validated as well [20].

Next, 12 out of the 24 articles studied adopt a mediating approach, studying one or more intervening variables on the relationship between BDAC and firm outcome variables. The most researched mediator is the presence of dynamic capabilities which refers to an organization's ability "to integrate, build, and reconfigure internal and external competences to address rapidly changing environments $[18$, p. 516] A few scholars [19 - 21] show a positive relationship between a firm's BDAC and the development of dynamic capabilities. These dynamic capabilities were in turn found to be positively associated with firm performance (from both a financial and market perspective). Dynamic capabilities also offer a valuable explanation of BDAC's influence on innovation [25]. Rather surprisingly, 10 out of 24 studies defined and investigated a direct relationship between a firm's BDAC and a firm level outcome without studying the relevance of a mediating variable. Different scholars [23 - 25] hypothesized and found a direct positive relationship with financial performance (only) while other scholars found a direct positive association with financial performance and other types of firm performance such as: market performance [10, 26], decision-making performance [30] supply chain sustainability [31], performance in terms of organizational agility or flexibility [32] and social or environmental performance $[30,31]$. The relationship between a firm's BDAC and the realization of a 
competitive advantage is thus still not fully explored, especially not when it comes to the impact on processlevel performance.

\section{Theoretical background and hypotheses}

We draw on the RBV in order to examine the impact of a firm's BDAC on the realization of a competitive advantage. The RBV relies on the principle that resources should be valuable, rare, imperfectly imitable and organized properly [23, p. 114, 32] and that firm competitiveness is a function of the strength, expert exploitation, and leveraging of these specific internal resources and capabilities [33, p. 531]. As the access to resources differs among firms due to incomplete markets and as the development of capabilities is contingent upon distinct behavioral patterns which are complex and involve both formal and informal processes, capabilities are assumed to build the foundation for sustainable competitive advantage [37].

Our research model conceptualizes BDAC dimensions as "having the attributes of complementarity and cospecialization, which work together in a synergistic fashion to achieve distinctive firm performance $[1, \mathrm{p}$. 117]." The tangible resources (i.e. data and technology) can, combined with the required human skills (i.e. both technical and managerial) create a BDAC in an organizational context. This in turn may serve as a source of competitive advantage [35, p. 176]. Based on this theory and the empirical evidence outlined in literature review, we hypothesize that:

H1: A firm's BDAC is positively associated with the realization of a competitive advantage.

Additionally, we argue that the effect is (partially) mediated by the improvement of three intermediate process-level outcomes: OMP, CMP and IMP. OMP is related to the efficiency and quality of a firm's operational processes [39]. CMP is related to the facilitation of customer selection, acquisition and retention [39]. IMP is related to the identification of opportunities and the efficiency of new product development [39].

Our approach relies on the IT business value approach which has become common in the Information Systems literature to better understand the relationship between IT and performance [40]. IT business value is defined as "the organizational performance impacts of information technology at both the intermediate process level and the organization wide level, and comprising both efficiency impacts and competitive impacts [38, p. 287]." Business processes are the mechanisms through which resources and capabilities get exposed to market processes where their ultimate value and ability to generate a competitive advantage are realized [39, p. 35]

Elbashir et al. [43] concluded that BI \& Analytics (BI\&A) comes with the improvement in the efficiency of internal processes such as enhanced staff productivity and the reduction of operational costs. According to Torres et al. [44] the operational efficiency and effectiveness of a firm's internal business processes, was positively associated with increased analytical dynamic capabilities. Wang et al. [45] found that BDA stimulates operational improvements while Lavalle et al. [15] found that BDA can help firms to manage risks, reduce costs and improve the visibility of the supply chain. According to Whiting [46], dashboards can help firms to collect and analyze performance data about the efficiency of internal processes and workflows. When the information is more easily accessible, less time is required to manipulate the data and to identify aspects that need attention so that improvement of operational processes is enabled [47]. Therefore, we assume that:

H2: A firm's BDAC is positively associated with a firm's competitive advantage through an improved operations management process (OMP).

Firms that score higher on the BI\&A maturity scale create, besides internal process efficiency benefits, also customer intelligence benefits that arise from a better understanding of the customer and the market $[45$, p. 7]. These benefits were found to be associated with business performance benefits [49]. Firms are able to better map customer wishes and (future) buying behavior resulting in better customer service [40, 47]. In addition, BI\&A systems enable customer segmentation which in turn helps firms to reduce marketing costs and simultaneously improve customer relationship management (CRM) [48, 49]. Increased customer satisfaction can improve customer loyalty [47] and retention [53] which in turn generates higher cash flows. CMP could therefore be an important mediator between BDA solutions and the realization of a competitive advantage [54]. This leads us to following hypothesis:

H3: A firm's BDAC is positively associated with a firm's competitive advantage through an improved customer management process (CMP).

Previous studies provide evidence on the relevance of innovation when researching the performance impact of BDA. It is argued that BDA can help firms to accelerate product innovation processes [55], stimulate strategic improvements [45] and 
experimentation $[53,54]$. BDA also holds potential for service innovation where the automation of customersensitive service provisions plays an important role in the creation of new value propositions [58]. Troilo et al. (2017) also concluded that analytics was positively related to service innovations, and more specifically: service process innovation, customer experience innovation and service concept innovation [59]. Further, we found evidence that (B)DA capabilities have a positive association with financial performance through an improved innovative capability [60] or the innovation process [61]. On the other hand, Mikalef et al. (2019) found that dynamic capabilities fully mediate the effect of a firm's BDAC on both incremental and radical innovation capabilities [62]. This effect is strengthen under high environmental dynamism. Therefore, we assume that:

H4: A firm's BDAC is positively associated with a firm's competitive advantage through improved innovation management process (IMP).

\section{Methodology}

All multi-item measurement instruments were taken from the existing literature. All constructs in the model were measured using a 7-point Likert scale. BDAC was adopted from Gupta \& George [10] measured as a third-order formative construct with - in total - 32 items. Internal business process performance was adopted from Hou [39], operationalized by three first order constructs: OMP performance (3 items), CMP performance ( 3 items) and IMP performance ( 5 items). Finally, competitive advantage was adopted from Schilke [63] as a second-order reflective construct, measured by two first-order constructs: financial performance (3 items) and strategic performance (3 items).

To estimate the research model, we collected information from two respondents with different functions in each company. Two cross-sectional surveys were developed: the (1) BDAC survey and the (2) Business Impact survey. Both surveys were pretested in advance to make sure all survey questions were understandable and reliable. The feedback led to a number of adaptations in the questions (e.g. longwinded questioning, repetitive measurement items etc.) (1) The BDAC survey was addressed to IT managers (or similar) in a company . The (2) Business Impact survey was targeted to the CEO's or other members of the top management team in the same company. This approach is so far rather scarce in empirical studies. Though, we are convinced that this appraoch reduces social desirability bias and measurement error as IT managers (or similar) were not asked to judge the impact of BDAC on the organization themselves and CEOs were not asked to answer on technical questions.

We contacted 1500 Belgian and 600 Dutch companies with at least 50 employees (random sampling). The surveys were distributed by e-mail or by direct message in LinkedIn. If a company was contacted by email, two reminders were sent (each after two weeks). One reminder was sent for the Linked-In messages (also after two weeks). After deleting incomplete surveys, 245 answers on the BDAC survey remained $(11,5 \%)$. With regard to the Business Impact survey, 208 complete observations (10\%). Based on the company e-mail addresses, the answers on both surveys could be matched. 112 full observations (5\%) were recorded which included responses of the IT managers and the business managers of the same firm and which could be subsequently used for analysis.

\section{Results}

The model was estimated with Partial Least Squares (PLS) using the SmartPLS software. The PLS method generates parameter estimates for the prediction of the variances of the latent variables. As regards the estimation of predicted variances, it must be articulated that SEM reports higher variances since mediating variables are fully examined so that both direct and indirect effects are considered. Interestingly, the PLS method does not require normally distributed data and can handle complex models without any problems. Finally, results remain robust for smaller datasets which is not unimportant given the rather small sample size [58, p. 315]

\subsection{Measurement model}

As a first step, we perform a CFA in order to evaluate the reliability of all first-order reflective latent variables, presented in table 1 . The reported loadings (all above the 0.70 threshold) indicate to what extent the items reflect the respective construct [65]. In addition, the Average Variance Extracted (AVE) (all above the 0.50 threshold) measures the amount of variance of a construct against measurement errors while the Composite Reliability (CR) (all above the 0.80 threshold) and the Cronbach's Alpha (CA) (all above the 0.70 threshold) show internal consistency of the items [66]. Discriminant validity of the construct indicators was examined by analyzing the loading of each indicator on its first-order. The examination of cross-loadings of all first-order constructs yielded support for discriminant validity. The indicators of the constructs loaded highly on their corresponding constructs in comparison to other constructs [67]. 
Next, we apply the assessment criteria for the formative constructs of our model. We first examined the weights and significance of the indicators on their respective formative construct. We found $\mathrm{BR} 2$ to be a non-significant indicator for the Basic resources (formative) construct. Nevertheless, we decided to not delete the indicator as formative constructs are likely to have indicators with non-significant weights, though providing a distinct contribution to the formative construct [68].

\section{Table 1. Reliability assessment of first-order reflective constructs}

\begin{tabular}{|c|c|c|c|c|c|}
\hline Construct & \multicolumn{2}{|c|}{$\begin{array}{l}\text { Item } \\
\text { loadings }\end{array}$} & CR & AVE & CA \\
\hline $\begin{array}{l}\text { Man. } \\
\text { Skills }\end{array}$ & $\begin{array}{l}\text { MS1 } \\
\text { MS2 } \\
\text { MS3 } \\
\text { MS4 } \\
\text { MS5 } \\
\text { MS6 }\end{array}$ & $\begin{array}{l}0.896 \\
0.923 \\
0.913 \\
0.899 \\
0.898 \\
0.925\end{array}$ & 0.966 & 0.826 & 0.958 \\
\hline $\begin{array}{l}\text { Tech. } \\
\text { Skills }\end{array}$ & $\begin{array}{l}\text { TS1 } \\
\text { TS2 } \\
\text { TS3 } \\
\text { TS4 } \\
\text { TS5 }\end{array}$ & $\begin{array}{l}0.765 \\
0.801 \\
0.923 \\
0.921 \\
0.930\end{array}$ & 0.940 & 0.758 & 0.918 \\
\hline $\begin{array}{l}\text { Data driven } \\
\text { culture }\end{array}$ & $\begin{array}{l}\text { DD1 } \\
\text { DD2 } \\
\text { DD3 } \\
\text { DD4 } \\
\text { DD5 }\end{array}$ & $\begin{array}{l}0.775 \\
0.874 \\
0.836 \\
0.851 \\
0.860 \\
\end{array}$ & 0.923 & 0.705 & 0.895 \\
\hline $\begin{array}{l}\text { Intensity of } \\
\text { org. } \\
\text { Learning }\end{array}$ & $\begin{array}{l}\text { OL1 } \\
\text { OL2 } \\
\text { OL3 } \\
\text { OL4 } \\
\text { OL5 } \\
\text { OL6 } \\
\end{array}$ & $\begin{array}{l}0.836 \\
0.910 \\
0.929 \\
0.894 \\
0.824 \\
0.836 \\
\end{array}$ & 0.950 & 0.761 & 0.937 \\
\hline $\begin{array}{l}\text { OMP } \\
\text { perf. }\end{array}$ & $\begin{array}{l}\text { OP1 } \\
\text { OP2 } \\
\text { OP3 }\end{array}$ & $\begin{array}{l}0.931 \\
0.930 \\
0.785\end{array}$ & 0.915 & 0.783 & 0.861 \\
\hline $\begin{array}{l}\text { CMP } \\
\text { perf. }\end{array}$ & $\begin{array}{l}\mathrm{CP} 1 \\
\mathrm{CP} 2 \\
\mathrm{CP} 3\end{array}$ & $\begin{array}{l}0.890 \\
0.939 \\
0.863 \\
\end{array}$ & 0.926 & 0.807 & 0.880 \\
\hline $\begin{array}{l}\text { IMP } \\
\text { perf. }\end{array}$ & $\begin{array}{l}\text { IP1 } \\
\text { IP2 } \\
\text { IP3 } \\
\text { IP4 } \\
\text { IP5 }\end{array}$ & $\begin{array}{l}0.840 \\
0.875 \\
0.860 \\
0.821 \\
0.821\end{array}$ & 0.925 & 0.712 & 0.899 \\
\hline $\begin{array}{l}\text { Financial } \\
\text { perf. }\end{array}$ & $\begin{array}{l}\text { FP1 } \\
\text { FP2 } \\
\text { FP3 }\end{array}$ & $\begin{array}{l}0.910 \\
0.946 \\
0.917\end{array}$ & 0.946 & 0.855 & 0.915 \\
\hline $\begin{array}{l}\text { Strategic } \\
\text { perf. }\end{array}$ & $\begin{array}{l}\text { SP1 } \\
\text { SP2 } \\
\text { SP3 }\end{array}$ & $\begin{array}{l}0.851 \\
0.796 \\
0.908\end{array}$ & 0.888 & 0.727 & 0.811 \\
\hline
\end{tabular}

The indicators' weights of the second-order constructs - (1) data $(\beta=0.363, p<.001$, VIF $=2.094)$, technology $(\beta=0.523, p<.001, \mathrm{VIF}=2.067)$, and basic resources $(\beta=0.311, \mathrm{p}<.001, \mathrm{VIF}=1.244)$ on the tangible construct, (2) technical skills $(\beta=0.473$, $\mathrm{p}$ $<.001, \mathrm{VIF}=1.812)$ and managerial skills $(\beta=0.619$, $\mathrm{p}<.001, \mathrm{VIF}=1.812)$ on the human skills construct, and (3) data-driven culture $(\beta=0.443, p<.001, \mathrm{VIF}=$
3.287) and the intensity of organizational learning ( $\beta$ $=0.619, \mathrm{p}<.001, \mathrm{VIF}=3.287)$ on the intangible construct - were statistically significant. Similarly, the indicators' weights of the third-order construct tangibles $(\beta=0.219, \mathrm{p}<.001, \mathrm{VIF}=1.956)$, human skills $(\beta=0.426, p<.001$, VIF $=2.064)$, and intangibles $(\beta=0.478, \mathrm{p}<.001, \mathrm{VIF}=2.575)$ - were significant. The Variance Inflation Factors (VIFs) are below the strict threshold of 3.3, indicating an absence of multicollinearity [18].

\subsection{Structural model}

The structural model from the PLS analysis is summarized in figure 1 , where the explained variance of endogenous variables $\left(\mathrm{R}^{2}\right)$ and the standardized path coefficients $(\beta)$ are presented. The significance of estimates (t-values) are obtained by performing a bootstrap analysis with 5000 resamples. We found a significant, positive effect of a firm's BDAC on the realization of a competitive advantage $(\beta=0.176, t=$ $1.995, \mathrm{p}<.05)$. H1 is thus accepted. Further, we found a significant, positive association between a firm's $\mathrm{BDAC}$ and the performance of the three measures for internal business process performance: operations management process $(\beta=0.221, \mathrm{t}=2.770 \mathrm{p}<.05)$, customer management process $(\beta=0.238, \mathrm{t}=2.676, \mathrm{p}$ $<.05)$ and innovation management process $(\beta=0.361$, $\mathrm{t}=4.094, \mathrm{p}<.001)$. These results confirm that a firm's BDAC, as high-level organizational capability, generates process-level impacts. However, with regard to the subsequent effect on the realization of a competitive advantage, we only found that an improved operations management process is positively associated with the realization of a competitive advantage $(\beta=0.414, t=3.575, \mathrm{p}<.001)$. As the direct association between a firm's BDAC and the realization of a competitive holds, OMP performance partially mediates the researched relationship. $\mathrm{H} 2$ is thus accepted while $\mathrm{H} 3$ and $\mathrm{H} 4$ are both rejected. The model explains $22.9 \%$ of the variation in competitive advantage while the variation in OMP, CMP and IMP is explained for respectively $4 \%, 4.7 \%$ and $12.2 \%$.

We take into consideration two control variables: company size and experience in data analytics. Results show no significant effect of firm size $(\mathrm{p}=.334)$. Traditionally, industry type is considered as well, however both firm and strategic performance are selfreporting measures where respondents were asked to rate their firm's performance relative to competitors. Purvis et al. [69] argued that a longer period helps organizations to develop expertise to use IT systems more effectively to generate business benefits. Results however show no significant effect of DA experience $(p=.605)$ on the firm's competitive advantage. 


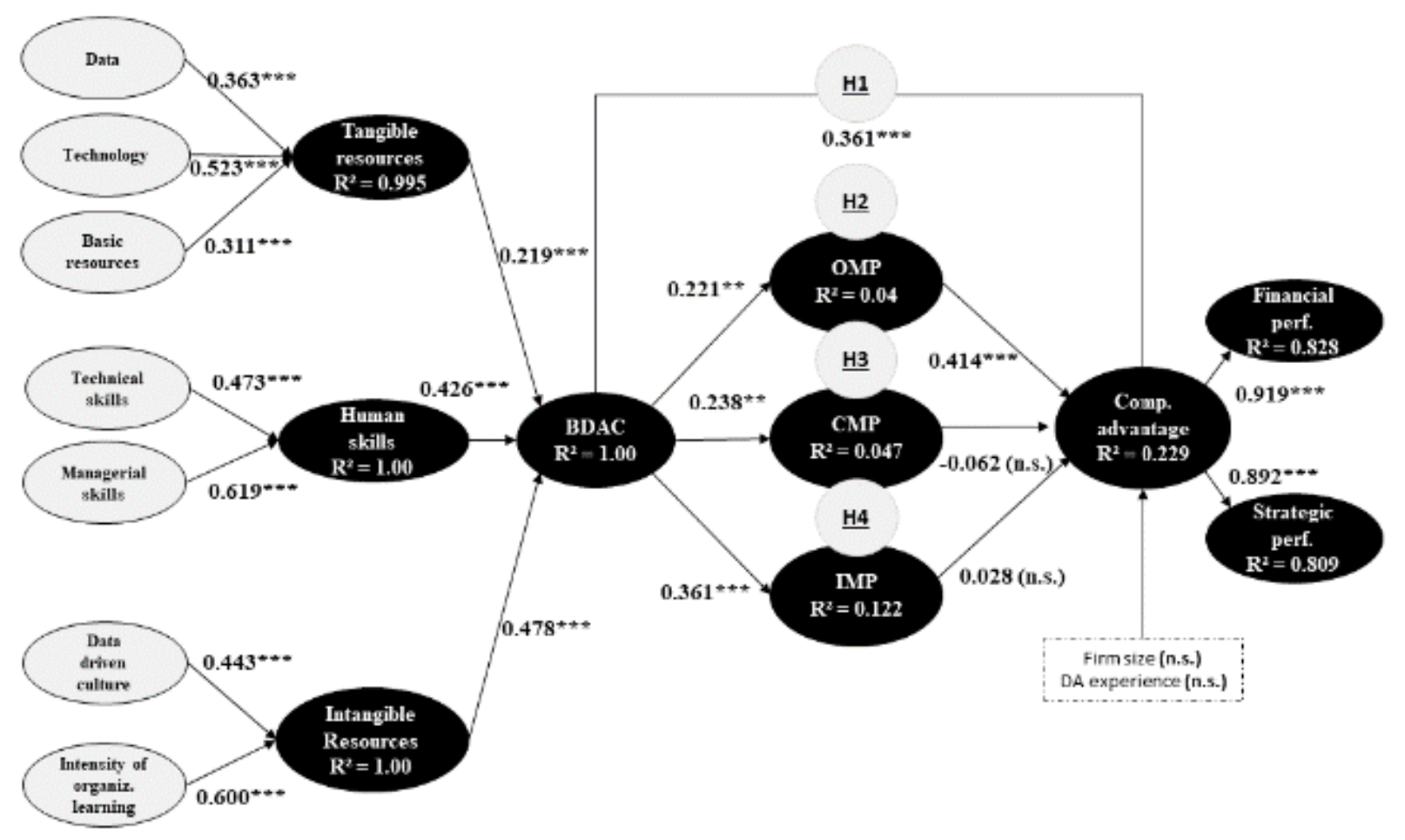

Figure 1. Research model

\section{Discussion}

The results show a direct and positive association between a firm's BDAC and the realization of a competitive advantage which manifests in increased financial and strategic performance.

This finding is in line with existing research $[1,10,25$, 28]. Beside the direct relationship, we found that the impact of a firm's BDAC on the realization of a competitive advantage is partially mediated through increased performance of the operations management process. Not surprising since greater efficiency in operations has a direct impact on cost savings and better organizational functioning. This positive association between business process performance and organizational performance is in accordance with the findings of Elbashir et al. [43]. The positive association between a firm's BDAC and the performance of the innovation management process is in accordance with, among others, Zhang et al. [61], Hooi et al. [70] and Upadhyay \& Kumar [29]. While an indirect effect could be found through OMP performance, a similar observation is - rather unexpected - not the case for CMP or IMP performance as mediator. One possible explanation is that attracting or retaining customers is not necessarily (or by definition) advantageous. Indeed, not all customers turn out to be profitable. It is argued that customers with a negative contribution can reach up to 30 percent in both $\mathrm{B} 2 \mathrm{C}$ and $\mathrm{B} 2 \mathrm{~B}$ markets [71]. Firms expanding their customer base are confronted with an average revenue per customer that may decline over time [72]. Furthermore, despite careful customer selection, customers can turn out to be very demanding en disrespectful which can impede employees' ability to maintain their productivity and motivation which can in turn negatively affect firm performance [73]. With regard to the non-significant impact of IMP performance on competitive advantage, evidence shows that 50 to 90 percent of new products fail [74] or, at least, that profit and growth - as a consequence of innovation - will be transitory and only last as long as the innovating firm can defend its position against rivals [75]. While OMP performance can have a direct impact on performance, the impact of CMP and IMP performance is probably lagged and subject to multiple conditions [76]. Visnjic et al. (2016) argued, for instance, that the returns for product innovation can be delayed which may impact our findings [77].

Furthermore, with respect to the measurement model, we observe that the first order constructs (i.e. data, technology, basic resources, technical skills, managerial skills, data driven culture and intensity of 
organizational learning) perfectly build the order constructs (i.e. tangible resources, human skills, intangible resources). The second order constructs perfectly build the third order construct (i.e. BDAC) at their turn. Next, we can conclude that human skills ( $\beta$ $=0.426)$ and intangible resources $(\beta=0.478)$ are relatively more important than the tangible resources ( $\beta=0.219$ ) for BDAC development. This in line with evidence from Kiron [78] and Vidgen et al. [79] arguing that organizational aspects are the biggest inhibitors in realizing business value from BDA investments.

\section{Implications and limitations}

Overall, this study contributes to the IS literature in general and the literature on the development and impact of a firm's BDAC specifically. Prior studies have evaluated different mediating variables, but empirical research on the relevance of process-level performance is lacking. Further, our study emphasizes the importance of capability development and the importance of managerial aspects (e.g. data driven culture, attracting enough talent) to realize a BDAC. With the measurement of Gupta \& George [10], we theoretically distinguishes BDAC from IT capabilities, highlighting that the value lies primary in gaining new insights and generating intelligence and evidence to support transformation or adaptation of the firm's operations. The latter also have implications from a practical point of view. Technical, organizational and human aspects of BDA should be considered during BDA projects in order to develop an effective BDAC.

We show that a firm's BDAC can strengthen the competitive advantage directly or through the fostering of operations management. Operations managers need to realize that insights gained through a strengthened BDAC can help internal processes run more efficiently and effectively. The internal functioning of the organization can be optimized and costs can be reduced, which can result in a better competitive position. The challenge seems to be bigger for marketing managers. While a firm's BDAC can facilitate customer selection, acquisition, and retention, it remains important to continuously monitor the customer value delivered, to make sure they are not detrimental to business performance. Finally, gained insights into the organization and organizational environment can stimulate or feed innovation. However, as innovation manager, you should take into account that the manner in which innovations are managed and brought to the market will partly determine whether a competitive advantage can be realized (or not).

Our study has also limitations. First, we tested our model using cross-sectional data which provides only limited insights. Longitudinal data can be interesting to track whether and how a firm's BDAC can evolve and what the impact is on organizational outcomes. Second, the combination with qualitative data can provide additional insights into the underlying mechanisms and processes. It could clarify how improved operations management is translated into a competitive advantage or why an improved customer and innovation management process is not automatically translated in a competitive advantage. Third, it should be mentioned that the explained variance of the firm's competitive advantage is acceptable but a bit lower compared to comparable studies. This leads us to conclude that while the performance of the internal business processes is important, more research is certainly needed into important drivers of competitive advantage that can be triggered by a better developed BDAC. Fourth, we adopted perceptual performance measures, which could be replaced by objective measures to present a concrete picture of BDAC's impact on firm performance. Fifth, it could be interesting to study the BDAC in a specific functional setting, for instance, marketing analytics or supply chain analytics. Last but not least, even though BDA is still hot and relevant, new technologies such as machine learning and AI needs attention as well and how capabilities can be developed around these emerging technologies.

From the above limitations, opportunities can arise for future research. Future work may continue to improve the BDAC model by identifying new big data resources. In addition, other relevant intervening variables can be taken into account to further unravel the relationship between a firm's BDAC and the realization of a competitive advantage. It could be interesting as well to check whether or not contextual variables or firm-specific characteristics might have an influence on the observed relationship between a firm's BDAC and the performance of internal business processes and the ultimate realization of a competitive advantage.

\section{Conclusion}

The objective of this study was to study the relationship between a firm's BDAC and the perceived realization of a competitive advantage (RQ1). We also introduced the performance of three intermediate internal business processes in order to test for mediation: the operations management process, the customer management process and the innovation 
management process (RQ2). From a theoretical point of view, we relied on Gupta \& George's third-order formative operationalization of the BDAC construct, the IT business value approach and the resource based view as base theory for hypothesis development. A direct positive relationship was found between a firm's BDAC and the perceived realization of a competitive advantage. An indirect effect was found for OMP performance, but not for CMP performance or IMP performance.

\section{References}

[1] S. Akter, S. F. Wamba, A. Gunasekaran, R. Dubey, and S. J. Childe, "How to improve firm performance using big data analytics capability and business strategy alignment?," Int. J. Prod. Econ., vol. 182, pp. 113-131, 2016.

[2] I. D. Constantiou and J. Kallinikos, "New games, new rules: Big data and the changing context of strategy," J. Inf. Technol., vol. 30, no. 1, pp. 44-57, 2015.

[3] Ö. Işik, M. C. Jones, and A. Sidorova, "Business intelligence success: The roles of BI capabilities and decision environments," Inf. Manag., vol. 50, no. 1, pp. 13-23, 2013.

[4] G. Phillips-Wren, L. S. Iyer, U. Kulkarni, and T. Ariyachandra, "Business analytics in the context of big data," Commun Assoc Inf Syst, vol. 37, 2015.

[5] T. S. Calvard, "Big data, organizational learning, and sensemaking: Theorizing interpretive challenges under conditions of dynamic complexity," Manag. Learn., vol. 47, no. 1, pp. 6582, 2016.

[6] A. Alharthi, V. Krotov, and M. Bowman, "Addressing barriers to big data," Bus. Horiz., vol. 60, no. 3, pp. 285-292, 2017.

[7] M. Colas, R. Nambiar, I. Finck, R. R. Singh, and J. Buvat, "Cracking the Data Conundrum: How Successful companies Make Big Data Operational.," 2014.

[8] H. Hu, Y. Wen, T. S. Chua, and X. Li, "Toward scalable systems for big data analytics: A technology tutorial," IEEE Access, vol. 2, pp. 652687, 2014.

[9] C. Dremel, S. Overhage, S. Schlauderer, and J. Wulf, "Towards a Capability Model for Big Data Analytics," Proc. der 13. Int. Tagung Wirtschaftsinformatik, pp. 1141-1155, 2017.

[10] M. Gupta and J. F. George, "Toward the development of a big data analytics capability," Inf. Manag., vol. 53, no. 8, pp. 1049-1064, 2016.

[11] N. Côrte-real, T. Oliveira, and P. Ruivo, "Assessing business value of Big Data Analytics in European firms.," J. Bus. Res., vol. 70, pp. 379-390, 2017.

[12] G. Ray, W. A. Muhanna, and J. B. Barney, "Information Technology and the Performance of the Customer Service Process: A Resource-Based Analysis," MIS Q., vol. 29, no. 4, pp. 625-652, 2005.

[13] D. Appelbaum, A. Kogan, M. Vasarhelyi, and Z.
Yan, "Impact of business analytics and enterprise systems on managerial accounting," Int. J. Account. Inf. Syst., vol. 25, no. March, pp. 29-44, 2017.

[14] R. Cosic, G. Shanks, and S. Maynard, "Towards a Business Analytics Capability Maturity Model," pp. 1-11, 2012.

[15] S. Lavalle, E. Lesser, R. Shockley, M. S. Hopkins, and N. Kruschwitz, "Big Data, Analytics and the Path From Insights to Value," MIT Sloan Manag. Rev., vol. 52, no. 2, pp. 21-32, 2011.

[16] S. F. Wamba, S. Akter, and C. Guthrie, "Making big data analytics perform: the mediating effect of big data analytics dependent organizational agility," Syst. d'Information Manag., vol. 25, no. 2, pp. 7-31, 2020.

[17] C. B. Jarvis, S. B. Mackenzie, P. M. Podsakoff, and C. Burke, "A Critical Review of Construct Indicators and Measurement Model Misspecification in Marketing and Consumer Research," vol. 30, no. September 2003, pp. 199218, 2004.

[18] S. Petter, D. Straub, and A. Rai, "Specifying Formative Constructs in Information Systems Research," MIS Q., vol. 31, no. 4, pp. 623-656, 2007.

[19] R. M. Grant, "The resource-based theory of competitive advantage: implications for strategy formulation," Calif. Manage. Rev., vol. 33, no. 3, pp. 114-135, 1991.

[20] M. Gupta and J. F. George, "Toward the development of a big data analytics capability," Inf. Manag., vol. 53, no. 8, pp. 1049-1064, 2016.

[21] D. Teece, G. Pisano, and A. Shuen, "Dynamic capabilities and strategic management," Strateg. Manag. J., vol. 18, no. 7, pp. 509-533, 1997.

[22] S. Akter, A. Gunasekaran, S. F. Wamba, M. M. Babu, and U. Hani, "Reshaping competitive advantages with analytics capabilities in service systems," Technol. Forecast. Soc. Change, vol. 159, 2020.

[23] C. C. H. Liu and N. Mehandjiev, "The effect of big data analytics capability on firm performance: A pilot study in China," Lect. Notes Bus. Inf. Process., vol. 381 LNBIP, no. December 2019, pp. 594-608, 2020.

[24] P. Mikalef, J. Krogstie, I. O. Pappas, and P. Pavlou, "Exploring the relationship between big data analytics capability and competitive performance: The mediating roles of dynamic and operational capabilities," Inf. Manag., vol. 57, no. 2, p. 103169, 2020.

[25] X. Xiao, Q. Tian, and H. Mao, "How the interaction of big data analytics capabilities and digital platform capabilities affects service innovation: A dynamic capabilities view," IEEE Access, vol. 8, 2020.

[26] S. Akter, S. F. Wamba, A. Gunasekaran, R. Dubey, and S. J. Childe, "How to improve firm performance using big data analytics capability and business strategy alignment?," Int. J. Prod. Econ., vol. 182, pp. 113-131, 2016.

[27] M. Anwar, S. Z. Khan, and S. Z. A. Shah, "Big Data 
Capabilities and Firm's Performance: A Mediating Role of Competitive Advantage," J. Inf. Knowl. Manag., vol. 17, no. 4, 2018.

[28] V. C. Gu, B. Zhou, Q. Cao, and J. Adams, "Exploring the relationship between supplier development, big data analytics capability, and firm performance," Ann. Oper. Res., 2021.

[29] P. Upadhyay and A. Kumar, "The intermediating role of organizational culture and internal analytical knowledge between the capability of big data analytics and a firm's performance," Int. J. Inf. Manage., vol. 52, no. February, 2020.

[30] S. Shamim, J. Zeng, Z. Khan, and N. U. Zia, "Big data analytics capability and decision making performance in emerging market firms: The role of contractual and relational governance mechanisms," Technol. Forecast. Soc. Change, vol. 161, no. September, 2020.

[31] S. Shokouhyar, M. R. Seddigh, and F. Panahifar, "Impact of big data analytics capabilities on supply chain sustainability," World J. Sci. Technol. Sustain. Dev., vol. 17, no. 1, pp. 33-57, 2020.

[32] T. Srimarut and W. Mekhum, "From supply chain connectivity (SCC) to supply chain agility (SCA), adaptability and alignment: Mediating role of big data analytics capability," Int. J. Supply Chain Manag., vol. 9, no. 1, pp. 183-189, 2020.

[33] R. Dubey et al., "Can big data and predictive analytics improve social and environmental sustainability?," Technol. Forecast. Soc. Change, vol. 144, no. June 2017, pp. 534-545, 2019.

[34] S. Jeble, R. Dubey, S. J. Childe, T. Papadopoulos, D. Roubaud, and A. Prakash, "Impact of Big Data \& Predictive Analytics on Supply Chain Sustainability: A Contingent Resource Based View," Int. J. Logist. Manag., vol. 47, pp. 459-469, 2018.

[35] J. B. Barney, "Firm Resources and Sustained Competitive Advantage," Journal of Management, vol. 17, no. 1. pp. 99-120, 1991.

[36] J. F. Henri, "Management control systems and strategy: A resource-based perspective," Accounting, Organ. Soc., vol. 31, no. 6, pp. 529558, 2006.

[37] G. Schreyögg and M. Kliesch-Eberl, "How dynamic can organizational capabilities be? Towards a dual-process model of capability dynamization," Strateg. Manag. J., vol. 28, no. 9, pp. 913-933, 2007.

[38] A. S. Bharadwaj, "A Resource-Based Perspective on Information Technology Capability and Firm Performance: An Empirical Investigation," MIS Q., vol. 24, no. 1, pp. 169-196, 2016.

[39] C. K. Hou, "Using the balanced scorecard in assessing the impact of BI system usage on organizational performance: An empirical study of Taiwan's semiconductor industry," Inf. Dev., vol. 32, no. 5, pp. 1545-1569, 2016.

[40] J. G. Mooney, V. Gurbaxani, and K. L. Kraemer, "A process oriented framework for assessing the business value of information technology," $A C M$ SIGMIS Database, vol. 27, no. 2, pp. 68-81, 1996.
[41] N. Melville, K. Kraemer, and V. Gurbaxani, "Review: Information Technology and Organizational Performance : An Integrative Model of IT Business Value," MIS Q., vol. 28, no. 2, pp. 283-322, 2004.

[42] G. Ray, J. B. Barney, and W. A. Muhanna, "Capabilities, business processes, and competitive advantage: Choosing the dependent variable in empirical tests of the resource-based view," Strateg. Manag. J., vol. 25, no. 1, pp. 23-37, 2004.

[43] M. Z. Elbashir, P. A. Collier, and M. J. Davern, "Measuring the effects of business intelligence systems: The relationship between business process and organizational performance," Int. J. Account. Inf. Syst., vol. 9, no. 3, pp. 135-153, 2008.

[44] R. Torres, A. Sidorova, and M. C. Jones, "Enabling firm performance through business intelligence and analytics: A dynamic capabilities perspective," Inf. Manag., vol. 55, no. 7, pp. 822-839, 2018.

[45] Y. Wang, L. Kung, and T. Anthony, "Technological Forecasting \& Social Change Big data analytics: Understanding its capabilities and potential benefits for healthcare organizations," Technol. Forecast. Soc. Chang., 2016.

[46] R. Whiting, "BPM Gets Smarter With A Little Help From BI.," Information Week, 2006. .

[47] R. Sabherwal and I. Becerra-Fernandez, Business intelligence practices, technologies, and management. Hoboken, New Jersey: Wiley, 2011.

[48] D. Raber, F. Wortmann, and R. Winter, "Towards the Measurement of Business Intelligence Maturity," Ecis, pp. 1-12, 2013.

[49] B. H. Sparks and J. T. Mccann, "Factors influencing Business Intelligence System use in decision making and organizational performance in decision making and organisational performance," Int. J. Sustain. Strateg. Manag., vol. 5, no. 1, pp. 31-54, 2015.

[50] H. J. Watson, J. A. Hoffer, and R. AndersonLehman, "Real-time business intelligence: Best practices at Continental Airlines," Inf. Syst. Manag., vol. 23, no. 1, pp. 7-18, 2006.

[51] Z. Jourdan, R. kell. Rainer, and T. Marshall, "Business intelligence: an analysis of the literature," IEEE Eng. Manag. Rev., vol. 36, no. 3, pp. 29-29, 2008.

[52] H. J. Watson, "Tutorial: Big Data Analytics: Concepts , Technologies, and Applications Tutorial: Big Data Analytics: Concepts, Technologies, and Applications," Commun. Assoc. Inf. Syst., vol. 34, pp. 1246-1269, 2014.

[53] S. Williams, "Power combination," Strateg. Financ., vol. 89, no. 11, pp. 1-8, 2008.

[54] R. Chumpitaz and N. G. Paparoidamis, "Service quality and marketing performance in business-tobusiness markets: Service quality and marketing performance in business-to-business markets: exploring the mediating role of client satisfaction," J. Serv. Theory Pract., no. January, 2004.

[55] Y. Zhan, K. H. Tan, G. Ji, L. Chung, and M. Tseng, "A big data framework for facilitating product innovation processes," Bus. Process Manag. J., vol. 
23, no. 3, pp. 518-536, 2017.

[56] S. Fosso Wamba, S. Akter, A. Edwards, G. Chopin, and D. Gnanzou, "How 'big data' can make big impact: Findings from a systematic review and a longitudinal case study," Int. J. Prod. Econ., vol. 165, pp. 234-246, 2015.

[57] K. H. Tan, Y. Z. Zhan, G. Ji, F. Ye, and C. Chang, "Harvesting big data to enhance supply chain innovation capabilities: An analytic infrastructure based on deduction graph," Int. J. Prod. Econ., vol. 165, pp. 223-233, 2015.

[58] C. Lehrer, A. Wieneke, J. vom Brocke, R. Jung, and S. Seidel, "How Big Data Analytics Enables Service Innovation: Materiality, Affordance, and the Individualization of Service," J. Manag. Inf. Syst., vol. 35, no. 2, pp. 424-460, 2018.

[59] R. E. Stake, Handbook of Qualitative Research, 2nd editio. Thousand Oaks, CA: Sage, 2000.

[60] A. Ashrafi, A. Zare Ravasan, P. Trkman, and S. Afshari, "The role of business analytics capabilities in bolstering firms' agility and performance," Int. J. Inf. Manage., vol. 47, no. December, pp. 1-15, 2019.

[61] H. Zhang, M. Song, and H. He, "Achieving the success of sustainability development projects through big data analytics and artificial intelligence capability," Sustain., vol. 12, no. 3, pp. 1-23, 2020.

[62] P. Mikalef, M. Boura, G. Lekakos, and J. Krogstie, "Big Data Analytics Capabilities and Innovation: The Mediating Role of Dynamic Capabilities and Moderating Effect of the Environment," $\mathrm{Br}$. J. Manag., vol. 30, no. 2, pp. 272-298, 2019.

[63] O. Schilke, "On the contingent value of dynamic capabilities for competitive advantage: the nonlinear moderating effect of environmental dynamism," Strateg. Manag. J., no. 35, pp. 179203, 2014.

[64] L. Lee, S. Petter, D. Fayard, and S. Robinson, "On the use of partial least squares path modeling in accounting research," Int. J. Account. Inf. Syst., vol. 12, no. 4, pp. 305-328, 2011.

[65] W. W. Chin, "Commentary Issues and Opinion on Structural Equation Modeling Clear Reporting," Mod. methods Bus. Res. Methodol. Bus. Manag., vol. 22, no. 1, pp. vii-xvi, 1998.

[66] C. Fornell and D. F. Larcker, "Evaluating Structural Equation Models with Unobservable Variables and Measurement Error," J. Mark. Res., vol. 18, no. 1, p. 39, 1981.

[67] J. F. Hair, G. T. M. Hult, C. M. Ringle, and M. Sarstedt, A primer on partial least squares structural equation modeling (PLS-SEM), 2nd ed. Sage, 2017.

[68] R. T. Cenfetelli and G. Bassellier, "Interpretation of formative measurement in information systems research," MIS Q. Manag. Inf. Syst., vol. 33, no. 4, pp. 689-707, 2009.

[69] R. Purvis, V. Sambamurthy, and R. Zmud, "The assimilation of knowledge platforms in organizations: An empirical investigation.," Org. Sci, vol. 12, no. 2, pp. 117-135, 2001.

[70] T. K. Hooi, N. H. B. Abu, and M. K. I. A. Rahim,
"Relationship of big data analytics capability and product innovation performance using smartPLS 3.2.6: Hierarchical component modelling in PLSSEM," Int. J. Supply Chain Manag., vol. 7, no. 1, pp. 51-64, 2018.

[71] M. Haenlein and A. M. Kaplan, "Unprofitable customers and their management," Bus. Horiz., vol. 52, no. 1, pp. 89-97, 2009.

[72] S. Gupta, D. R. Lehmann, and J. Stuart, "Valuing customers," J. Mark., vol. 23, no. 3, pp. 24-29, 2004.

[73] V. Mittal, M. Sarkees, and F. Murshed, "The right way to manage unprofitable customers," Harv. Bus. Rev., vol. 86, no. 4, 2008.

[74] S. Heidenreich and P. Spieth, "Why Innovations fail - the case of passive and active innovation resistance," Int. J. Innov. Manag., vol. 17, no. 05, pp. 1-42, 2013.

[75] L. G. Tornatzky et al., The process of technological innovation - reviewing the literature. National Science Foundation, 1983.

[76] D. Wang, X. Zhao, and Z. Zhang, "The Time Lags Effects of Innovation Input on Output in National Innovation Systems: The Case of China," Discret. Dyn. Nat. Soc., 2016.

[77] I. Visnjic, F. Wiengarten, and A. Neely, "Only the Brave: Product Innovation, Service Business Model Innovation, and Their Impact on Performance," $J$. Prod. Innov. Manag., vol. 33, no. 1, pp. 36-52, 2016.

[78] D. Kiron, "Lessons from becoming a data-driven organization.," MIT Sloan Manag. Rev., vol. 58, pp. 1-13, 2017.

[79] R. Vidgen, S. Shaw, and D. B. Grant, "Management challenges in creating value from business analytics," Eur. J. Oper. Res., vol. 261, no. 2, pp. 626-639, 2017. 